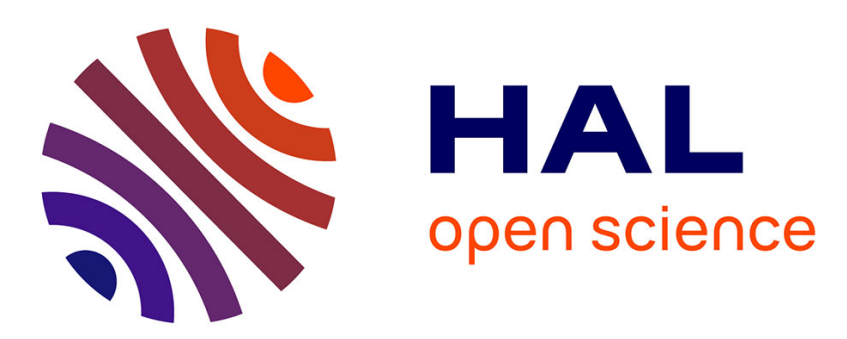

\title{
Diffusion of jets with annular counterflow and small diameter ratio
}

Dariusz Asendrych, Michel Favre-Marinet

\section{To cite this version:}

Dariusz Asendrych, Michel Favre-Marinet. Diffusion of jets with annular counterflow and small diameter ratio. AIAA Journal, 2004, 42 (11), pp.2385-2387. 10.2514/1.2616 . hal-00204635

\section{HAL Id: hal-00204635 \\ https://hal.science/hal-00204635}

Submitted on 10 Feb 2020

HAL is a multi-disciplinary open access archive for the deposit and dissemination of scientific research documents, whether they are published or not. The documents may come from teaching and research institutions in France or abroad, or from public or private research centers.
L'archive ouverte pluridisciplinaire HAL, est destinée au dépôt et à la diffusion de documents scientifiques de niveau recherche, publiés ou non, émanant des établissements d'enseignement et de recherche français ou étrangers, des laboratoires publics ou privés. 


\section{Diffusion of Jets with Annular Counterflow and Small Diameter Ratio}

\author{
Dariusz Asendrych* \\ Technical University of Czestochowa, \\ 42-200 Czestochowa, Poland \\ and \\ Michel Favre-Marinet ${ }^{\dagger}$ \\ Institut National Polytechnique de Grenoble, \\ 38000 Grenoble, France
}

\section{Nomenclature}

$D_{1} \quad=$ inner diameter of the central nozzle in the exit plane, $\mathrm{m}$

$D_{2}=$ inner diameter of the collar, $\mathrm{m}$

$L=$ length of the collar, $\mathrm{m}$

$R=$ suction ratio, $-U_{2} / U_{1}$

$R e=$ Reynolds number based on the central jet characteristics, $U_{1} D_{1} / v$

$U_{1} \quad=$ bulk velocity of the central jet in the nozzle exit plane, $\mathrm{m} \cdot \mathrm{s}^{-1}$

$U_{1 b}=$ velocity in the collar exit plane, $\mathrm{m} \cdot \mathrm{s}^{-1}$

$U_{2}=$ bulk velocity of the aspirated flow in the nozzle exit plane, $\mathrm{m} \cdot \mathrm{s}^{-1}$

$U(x)=$ longitudinal mean velocity, $\mathrm{m} \cdot \mathrm{s}^{-1}$

$u^{\prime}(x)=$ turbulent velocity fluctuation $\mathrm{rms}, \mathrm{m} \cdot \mathrm{s}^{-1}$

$w \quad=$ annular slot width in the nozzle exit plane, $\left(D_{2}-D_{1}\right) / 2, \mathrm{~m}$

$x=$ distance to the central nozzle exit plane, $\mathrm{m}$

$\Theta=$ boundary-layer momentum thickness in the nozzle exit plane, $\mathrm{m}$

$v \quad=$ kinematic viscosity, $\mathrm{m} \cdot \mathrm{s}^{-2}$

\section{Introduction}

A NEW technique was proposed by Strykowski and Wilcoxon ${ }^{1}$ (SW) several years ago for improving mixing in axisymmetric jets. In their facility, a countercurrent flow was produced near the jet exit, giving rise to enhancement of the initial jet instabilities. The annular counterflow was created by applying suction to an annular collar placed around the jet nozzle. The authors studied jets exhausting from a nozzle with a large area contraction ratio and a large collar/jet diameter ratio (2). They have shown that the initial jet turbulent activity and diffusion are significantly increased by a strong counterflow. Such a dramatic increase of mixing was also observed in a tube jet with a small gap between the collar and the inner nozzle. ${ }^{2,3}$ These results have confirmed the interest of using counterflow for the control of jet mixing. The technique also seems very promising for applications to combustion. ${ }^{4,5}$ Recently, Asendrych and Drobniak ${ }^{6}$ investigated the thermal field of nonisothermal countercurrent jets.

The aim of this Note is to describe the effects of a counterflow on the jet development when a narrow gap between the collar and the inner nozzle is used.

\section{Experimental Setup and Instrumentation}

The experimental setup consisted of a settling chamber followed by an axisymmetric nozzle discharging into ambient air. The settling chamber was supplied with compressed air by the network of the laboratory. The flow rate was controlled by sets of sonic throat orifices of different sizes placed upstream of the settling chamber. The nozzle is shown in Fig. 1. It was built with a large area contraction ratio (19.5) and an exit diameter $D_{1}(20 \mathrm{~mm})$. A countercurrent flow was created in a coannular slot of width $w(3.5 \mathrm{~mm})$ connected to a vacuum cleaner. The slot used in the present facility $\left(w / D_{1}=0.175\right)$ was much narrower than in SW's experiment $\left(w / D_{1}=0.5\right)$.

A suction collar of constant cross-sectional area was placed at the nozzle exit to form a cavity of length $L(20 \mathrm{~mm})$ and diameter $D_{2}$ $(27 \mathrm{~mm})$ concentric to the jet. It was aimed at producing a counterflow of significant velocity within the first jet diameter. It should be mentioned that SW's experiment was conducted using a diverging collar with the half-angle of $7 \mathrm{deg}$.

The origin of the $x$ axis is at the central nozzle exit (Fig. 1). The jet bulk velocity $U_{1}$ and the counterflow bulk velocity $U_{2}$ were defined in the central nozzle exit plane $(x=0)$. They were obtained by flow rate measurements using flow meters. The dimensionless parameters are the Reynolds number $\left(R e=U_{1} D_{1} / \nu\right)$ and the suction ratio $\left(R=-U_{2} / U_{1}\right)$.

The measurements were performed by single-channel hot-wire anemometry (with wire diameter of $5 \mu \mathrm{m}$, constant temperature anemometer Model AALAB-AN-1003) and all the data presented concern the longitudinal velocity vector component. Data acquisition and processing were performed via a 15 -bit A/D converter (IOtech model 488/16) connected to a Macintosh IIci computer. Laser-sheet visualizations were performed by using a $15-\mathrm{W}$ copper laser pulsed at $10 \mathrm{kHz}$. The laser sheet was produced by using a cylindrical lens and was about $1 \mathrm{~mm}$ thick. The central jet was seeded with incense smoke. The pictures were recorded with a videocamera at $50 \mathrm{frames} / \mathrm{s}$ at a shutter speed of $1 / 1000 \mathrm{~s}$.

\section{Jet Diffusion and Turbulent Activity}

The bulk velocity $U_{1}$ was kept constant $\left(U_{1}=10 \mathrm{~m} / \mathrm{s}, R e=1.3 \times\right.$ $10^{4}$ ), whereas $U_{2}$ and subsequently the suction ratio $R$ were varied during the experiments. Measurements at the nozzle exit $\left(x / D_{1}=0.05\right)$ showed that the boundary layer was laminar with a momentum thickness $\Theta=0.086 \mathrm{~mm}\left(D_{1} / \Theta=232\right)$. Two sets of measurements gave 2.67 and 2.53 for the shape factor. The turbulent intensity on the jet axis was $0.8 \%$. The position of the jet axis was checked by measurements of transverse velocity profiles in the far field $\left(x / D_{1}=20\right)$.

As in SW's experiments, the effects of counterflow on the jet were very weak in the absence of a collar at the nozzle exit. In addition, the jet characteristics were slightly affected by the collar when there was no counterflow, as presented later. On the contrary, the jet diffusion was significantly increased when the collar was placed at the jet exit and suction was applied to the slot at the same time.

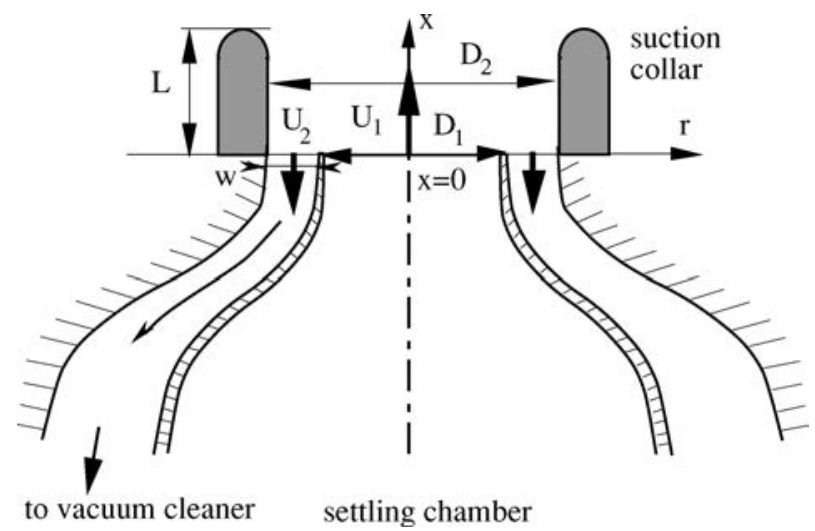

Fig. 1 Sketch of the nozzle with counterflow.
*Assistant Professor, Institute of Thermal Machinery, al. Armii Krajowej 21

${ }^{\dagger}$ Professor; also Head, Heat and Mass Transfer Group, Laboratoire des Ecoulements Géophysiques et Industriels, B.P. 53X, Institut National Polytechnique de Grenoble, Université Joseph Fourier, Centre National de la Recherche Scientifique, 38041 Grenoble, France. 


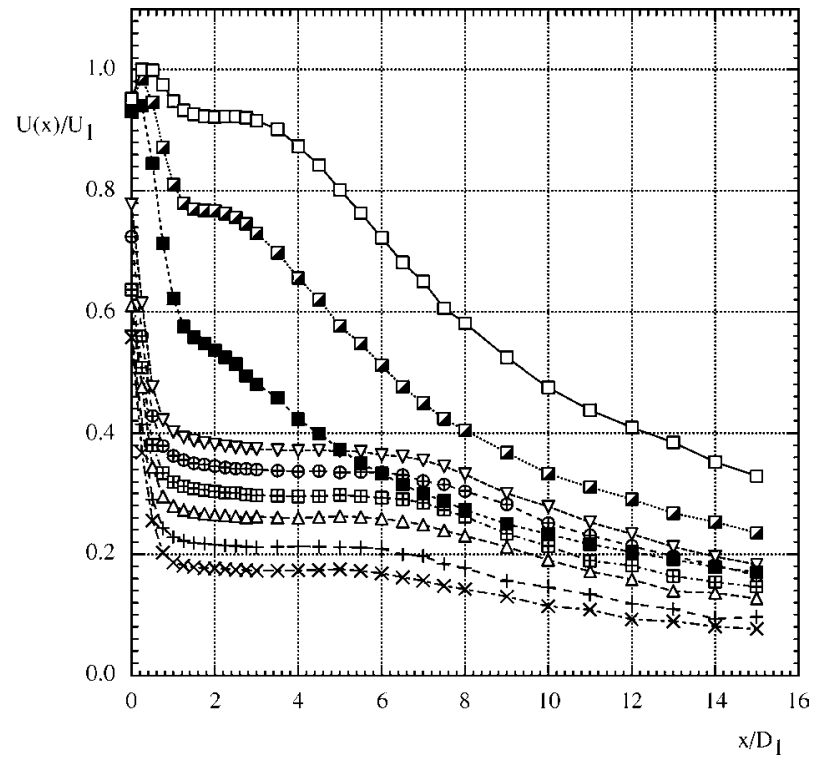

Fig. 2 Axial mean velocity profiles: $R=\square, 0 ; \square, 0.201 ; \square, 0.102$; $\nabla, 0.281 ; \oplus, 0.361 ;$ 田, $0.438 ; \triangle, 0.514 ;+, 0.605 ;$ and $X, 0.7$.

Figure 2 shows the downstream evolution of the jet-axis mean velocity $U(x)$ normalized by the bulk velocity $U_{1}$. Two distinct regimes may be clearly identified in Fig. 2:

1) For $R \leq 0.2, U(x)$ decreases rapidly in the collar $(0 \leq x /$ $\left.D_{1} \leq 1\right)$, then more slowly downstream. The shape of $U(x) / \bar{U}_{1}$ is like that of the jet with counterflow as observed by SW. However, the decrease of $U(x)$ in the collar is most probably due to the confinement of the central jet, which is more pronounced in the present arrangement.

2) For $R \geq 0.28$, the initial decrease of $U(x)$ is even faster than in the preceding regime. The mean velocity reaches a plateau $\left(1 \leq x / D_{1} \leq 5\right)$ before decreasing again. This surprising result may be understood as follows. For large values of $R$ and the present small value of $w / D_{1}$, a significant fraction of the flow rate issuing from the central nozzle is probably ingested by the aspiration slot. Furthermore, the fraction of the aspirated flow rate coming from the ambient air is significantly reduced due to the small difference between the diameters of the collar and the inner nozzle. It is likely that the aspirated flow rate comes entirely from the central nozzle jet for large values of $R$. In these conditions, the central jet is expected to completely fill the collar in its downstream part. In fact, this hypothesis is supported by visualizations that show that the diameter of the jet in the collar exit plane is close to $D_{2}$ for $R>0.2$ (Fig. 3). Coherent vortices similar to those of a standard jet may be observed in Fig. 3 .

The aforementioned hypothesis was also tested by rescaling the jet-axis mean velocity with the velocity in the collar exit plane: $U_{1 b}=U\left(x / D_{1}=1\right)$. Figure 4 displays $U_{1 b} / U(x)$ as a function of $x / D_{2}$. A linear least-squares regression over the data obtained for $0.281 \leq R \leq 0.514$ and $5 \leq x / D_{2} \leq 15$ gives the slope $m=0.188$. The results corresponding to $R=0$ are scaled with $U_{1}$ and $D_{1}$ and are drawn in the same graph with the same origin. The slope $m$ is only slightly smaller $(m=0.179)$ than that for the case with suction. It is worth noting that the straight line corresponding to the case with suction is shifted downstream by $D_{2}$ when compared to the case without suction. This shift is approximately equal to the collar length. Figures 3 and 4 therefore suggest that a high counterflow level $(R \geq 0.28)$ gives birth to a jet of initial value $U_{1 b}$ and initial diameter $D_{2}$ for these conditions of small diameter ratio.

The differences in the response of the jet to varying suction rates are also highlighted by Fig. 5a, which displays the distribution of the turbulent velocity fluctuation $\mathrm{rms} u^{\prime}(x) / U_{1}$ along the jet axis. Very low values of $u^{\prime}(x) / U_{1}$ are observed at the collar exit $\left(x / D_{1}=1\right)$ for $R \geq 0.28$, whereas $u^{\prime}(x) / U_{1}$ increases rapidly from the nozzle exit plane for the lowest suction rates. When $u^{\prime}(x)$ is normalized by the local mean value $U(x)$ (Fig. 5b), the results almost collapse

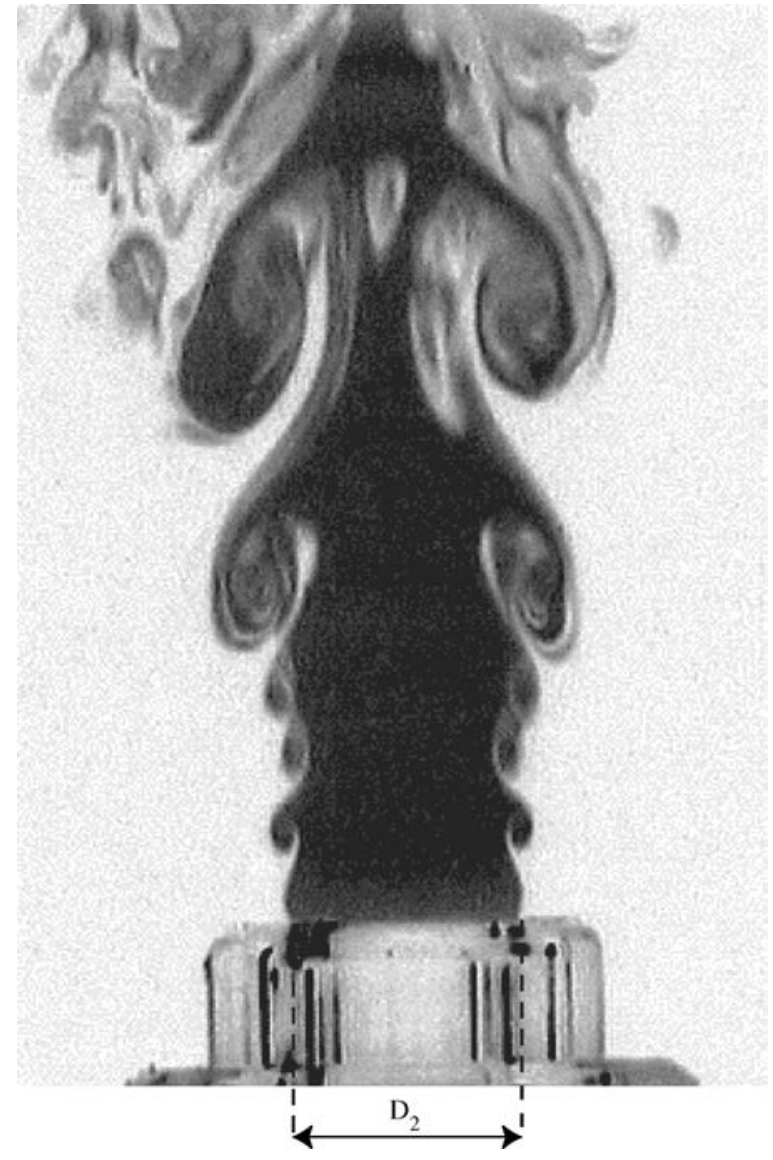

Fig. 3 Laser-sheet visualization $(R=0.361)$.

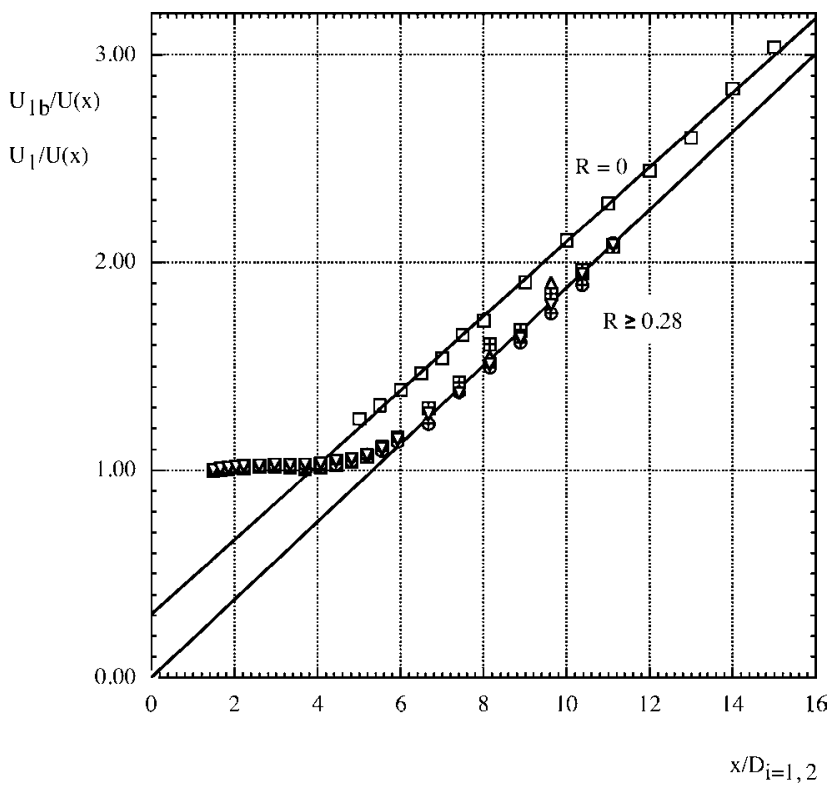

Fig. 4 Axial mean velocity profiles: scaling with $U_{1 b}$ and $D_{2}$ for $R \geq$ 0.28 and scaling with $U_{1}$ and $D_{1}$ for $R=0$. Symbols are the same as in Fig. 2.

in the first three diameters for $R \geq 0.28$. The initial rise is shifted downstream by a distance of the order of $L$ when compared to the case without suction. These results again confirm the previous interpretation of the mean velocity results for the cases of strong suction. The downstream evolution of $u^{\prime}(x) / U(x)$ seems to depend on $R$; however, all the curves tend to a plateau of approximately 0.25 like the jet without suction. The turbulent intensity exhibits a significant increase in the first five diameters for $R=0.201$. 


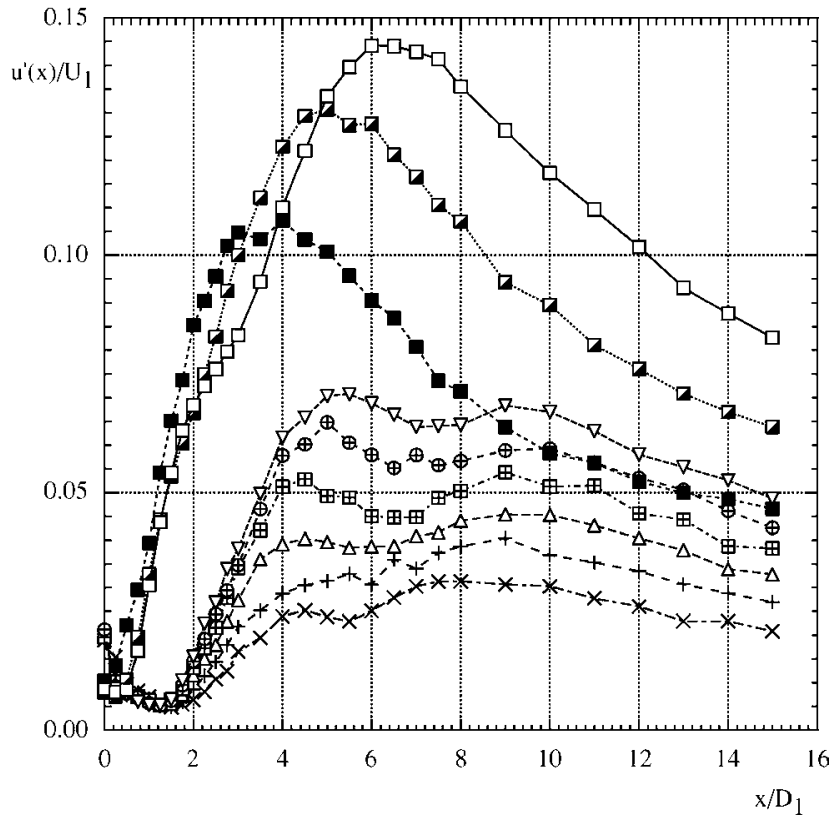

a)

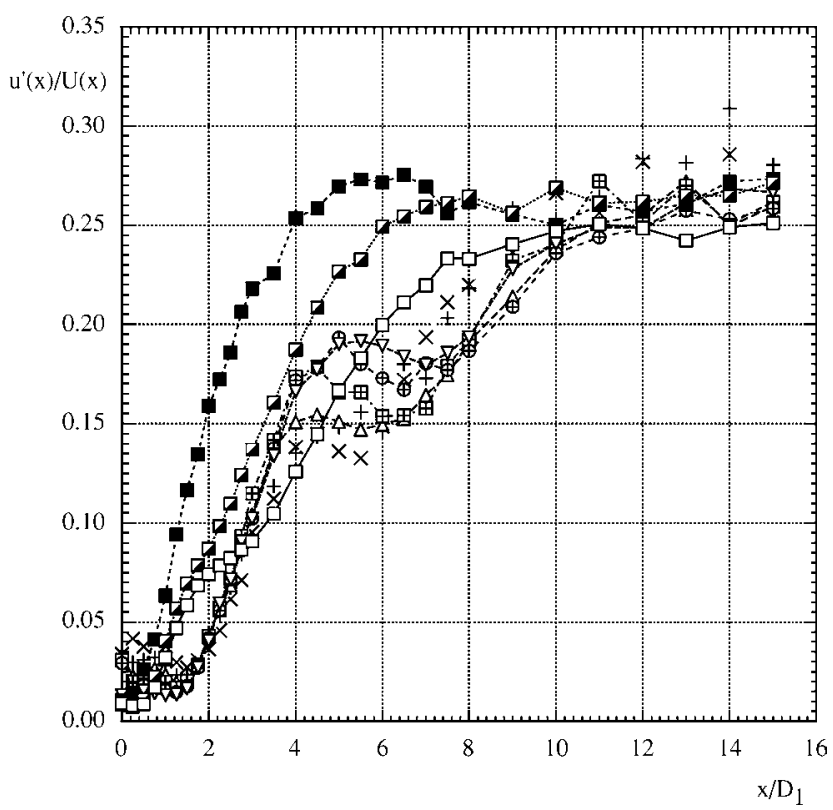

b)

Fig. 5 Axial profiles: a) turbulent velocity fluctuation rms and b) turbulent intensity. Symbols are the same as in Fig. 2.

\section{Conclusions}

The present results clearly show the existence of two regimes in the diffusion of jets with annular counterflow and small diameter ratio. For $R \leq 0.2$, the combination of a high level of suction and a narrow slot gives rise to a strong enhancement of the jet diffusion and turbulent activity. However, it has been shown ${ }^{3}$ that a fraction of the central flow rate is ingested into the slot for a tube jet and the same diameter ratio. Furthermore, this fraction grows with $R$. It is likely that the same phenomenon occurs with the present nozzle. This probably contributes to increase the spreading of the central jet and to accelerate the decrease of $U(x)$ inside the collar (Fig. 2). For $R \geq 0.28$, the central jet completely fills the collar exit section and effect of the suction is simply to give birth to a standard jet of reduced initial mass flow rate and increased diameter. It is clear that this second regime is of minor interest for practical applications.

\section{Acknowledgment}

The authors acknowledge the region Rhône-Alpes for supporting the visit of D. Asendrych in Grenoble.

\section{References}

${ }^{1}$ Strykowski, P., and Wilcoxon, R. K., "Mixing Enhancement Due to Global Oscillations in Jets with Annular Counterflow," AIAA Journal, Vol. 31, No. 3, 1993, pp. 564-570.

${ }^{2}$ Boguslawski, A., Favre-Marinet, M., and Abdulwahab, A., "Contrôle des Jets par Écoulement à Contre-Courant," Comptes Rendus de l'Académie des Sciences, Série IIb, Vol. 327, 1999, pp. 589-595.

${ }^{3}$ Favre-Marinet, M., and Boguslawski, A., "Jet Control by Counterflow," Turbulence and Shear Flow Phenomena 1, edited by S. Banerjee and J. K. Eaton, Begell House, New York, 1999, pp. 659-664.

${ }^{4}$ Lourenco, L., Shen, H., Krothapalli, A., and Strykowski, P., "WholeField Measurements on an Excited Premixed Flame Using On-Line PIV," 8th International Symposium on Applications of Laser Techniques to Fluid Mechanics, Springer-Verlag, Berlin, 1996, pp. 425-437.

${ }^{5}$ Chan, S. M. S., Torii, S., and Yano, T., "Enhancement of Turbulent Jet Diffusion Flame Blowout Limits by Annular Counterflow," International Journal of Energy Research, Vol. 25, No. 12, 2001, pp. 1091-1105.

${ }^{6}$ Asendrych, D., and Drobniak, S., "Experimental Analysis of the Flowfield in Non-Isothermal Countercurrent Jets," Advances in Turbulence IX, edited by I. P. Castro, P. E. Hancock, and T. G. Thomas, CIMNE, Barcelona, 2002, p. 839. 